\title{
COVID-19 and Insurance market returns in emerging and developed markets: A comparative study based on Wavelet methods
}

\section{Zeeshan Fareed}

Huzhou University https://orcid.org/0000-0003-1971-8867

Najaf Iqbal ( $\square$ najaf_iqbal@live.com )

Anhui University of Finance and Economics https://orcid.org/0000-0001-6398-9918

\section{Research Article}

Keywords: COVID-19, Insurance industry, Wavelet analysis, Emerging markets, Developed markets

Posted Date: October 19th, 2020

DOI: https://doi.org/10.21203/rs.3.rs-93926/v1

License: (c) (1) This work is licensed under a Creative Commons Attribution 4.0 International License.

Read Full License 


\title{
COVID-19 and Insurance market returns in emerging and developed markets: A comparative study based on Wavelet methods
}

\begin{abstract}
This study investigates the co-movement nexus between COVID-19 and insurance industry returns for emerging and developed markets using a wavelet-based framework. Analysis on the daily observations from $22^{\text {nd }}$ January 2020 to $14^{\text {th }}$ September 2020 reveals that insurance returns (INS) responded strongly and negatively, right after the onset of the global COVID-19 outbreak, but asymmetrically later. Additionally, the devastation brought to INS is comparatively more severe but short-lived for emerging markets. The wavelet-based Granger causality and correlation confirm the robustness of our results. These findings are important for policymakers and investors in the insurance industry in the aftermath of COVID-19.
\end{abstract}

Keywords: COVID-19; Insurance industry; Wavelet analysis; Emerging markets; Developed markets

\section{Introduction}

Recently, we are passing through an unprecedented time in human history. Despite all the technological and economic progress we made, and the abundance of resources we have, everyone felt helpless at least for some period of time, in front of nature during the COVID-19 outbreak (Goodell, 2020). The global number of confirmed cases and deaths has surpassed 30 million and 1 million (as of $24^{\text {th }}$ September 2020), respectively, according to the World Health Organization (WHO, 2020). The devastation brought by the COVID-19 has reminded us about the dire challenges of pandemics that we may have to face in the future also. While it may be impossible to avoid these kinds of risks to human lives in entirety, there are ways to mitigate the shattering 
effects of such events. The insurance industry is the prime channel for hedging such risks in today's world (Chen et al., 2020). Extensive research is being carried out on multiple (financial and nonfinancial) aspects of the COVID-19 pandemic. For example, several studies have discussed the stock markets' reaction to the COVID-19 epidemic (Akhtaruzzaman et al., 2020; Azimli, 2020; Baek et al., 2020; Cepoi, 2020; Ciner, 2020; Erdem, 2020; Li et al., 2020; Mazur et al., 2020; Okorie \& Lin, 2020; Topcu \& Gulal, 2020; Zaremba et al., 2020; Zhang et al., 2020). Others have explored the impact of this shock on digital assets and commodity markets (Conlon \& McGee, 2020; Corbet et al., 2020; Goodell \& Goutte, 2020; Ji et al., 2020; Mensi et al., 2020; Mnif et al., 2020). However, the insurance industry's response to the pandemic still needs vivid exploration. Figure 1 shows the time trend of new COVID-19 infections worldwide.

\section{$<<$ Insert Figure 1 here $>>$}

Because of heterogeneous market characteristics and varying business models with diverse customer bases in emerging and advanced countries (Mnif et al., 2020), insurance industries of both types of economies are expected to behave differently in response to the COVID-19 pandemic. The Swiss-Re reports that total premium income in developed markets (life and nonlife insurance) will fall by $4 \%$ due to COVID-19 this year, and is expected to recover with a positive growth of $2 \%$ in 2021 . In contrast, the insurance premium growth in emerging markets will remain positive, up 1\% and 7\% in 2020 and 2021, respectively (Swiss Re, 2020). Figure 2 compares the insurance premium (life and non-life) growth with respect to GDP growth in emerging and developed economies. Figure 3 illustrates the insurance market returns indices in emerging and developed economies.

$<<$ Insert Figure 2 here $>>$ 


\section{$<<$ Insert Figure 3 here $>>$}

The insurance industry could be affected by the COVID-19 in two broad categories; premiums and claims. While it is clear that the claims might have skyrocketed due to increased unemployment (payments to unemployment insurance buyers), hospitalizations (increased payments in case of health insurance policyholders), deaths (huge lump sum and annuity payments for life insurance), and business closures (payments against natural disasters), the impact on the premium is again expected to be twofold. First, there may be a huge loss of premium income due to reduced family, health, and life insurance sales resulting from wide-scale lockdowns with no direct interaction between salespersons and potential insurance policy buyers. Second, online insurance sales might boom due to the increased health and life risks brought by the pandemic. People might want to hedge their huge payment risks due to potential illnesses caused by the epidemic or overall deteriorating health scenario. Correspondingly, increased unemploymentinsurance sales, and corporate-insurance sales may increase the premium income of the insurance companies.

The elasticity of corporate insurance demand after a catastrophic incident can explain if the insurance industry returns will be affected positively or negatively. One of the very few empirical papers on this important topic uses the data on 1800 large U.S. corporations and concludes that the insurance industry gests a boom in premium income after catastrophic incidents (Michel-Kerjan et al., 2015). Another study using 43 large catastrophic-insured incidents since 1970, finds a significant increase in industry revenues and stock returns of insurance brokers, right after such incidents (Ragin \& Halek, 2016). The COVID-19 has had a severe negative impact on the Chinese insurance industry and caused a reduction in all kinds of inflows, including both commercial and individual premiums. The growth rate of gross premium fell by $9.53 \%$ as compared with 2019 
(Wang et al., 2020). By performing a qualitative study on the opinions of industry experts and professionals in Ethiopia, Worku and Mersha (2020) find that COVID-19 had a catastrophic effect on the Ethiopian insurance industry. However, an interesting question has emerged in the context of COVID-19. Whether an event like this can be insured or not (Goodell, 2020)?

The possibility of positive changes in insurance returns after a catastrophic incident as supported by the literature, and the recent negative effects of COVID-19 shock for this industry in few countries as evidenced by few studies, calls for a fresh and definitive inquiry into this gravely important area. As it's difficult to collect the data on premiums collected, and claims handled for a vast majority of firms from all the emerging and advanced economies during COVID-19, we can gauge the overall impact from the changes in the daily market prices/returns of publicly traded insurance companies. More specifically, we use the daily insurance returns indices for advanced and emerging markets, representing the broad market performance of insurance industry stocks.

\section{Data description and sources}

The COVID-19 outbreak is represented by "daily new infections worldwide", and data is sourced from the Bing COVID-19 Tracker $^{1}$. Insurance market returns in developed and emerging economies are represented by the "Nasdaq developed markets insurance index" $(I N S-D M)^{2}$ and "Nasdaq emerging markets insurance index" $(I N S-E M)^{3}$, respectively, and collected from the Nasdaq official website. The sample period ranges from $22^{\text {nd }}$ January 2020 to $14^{\text {th }}$ September 2020. The INS total returns index is derived from the following Equation (1).

\footnotetext{
${ }^{1}$ Bing COVID-19 Tracker (https://www.bing.com/covid)

2 INS-DM is comprised the index of 25 developed countries, including Austria, Australia, Belgium, Canada, Switzerland, Germany, Denmark, Spain, Finland, France, UK, Greece, Hong Kong, Ireland, Italy, Japan, Korea, Norway, Netherland, New Zealand, Portugal, Sweden, Singapore, United States.

${ }^{3}$ INS-EM is comprised the index of 20 emerging countries, Including Brazil, China, Colombia, Chile, Czech Republic, Egypt, Hungary, Indonesia, India, Morocco, Mexico, Malaysia, Poland, Peru, Philippines, Russia, Thailand, Turkey, Taiwan, South Africa.
} 


$$
T R I_{t}=T R I_{t-1} \frac{\left(P R I_{t}+I D P_{t}\right)}{P R I_{t-1}}
$$

Where, $T R I_{t}$ is the value of "total return index" on the current day, and $T R I_{t-1}$ shows its closing value on the previous day. $P R I_{t}$ and $P R I_{t-1}$ represents the value of the "price return index" on present day and the previous day (closing value), respectively. Finally, $I D P_{t}$ indicates the "index dividend points".

\section{Methodology}

To study the asymmetric covariance nexus between COVID-19 and insurance market returns in a different time and frequency domains, we have employed the novel methods of time series analysis, such as "continuous wavelet transforms" (CWT) and "wavelet coherence" (WTC). Further, we check the robustness through "wavelet based Granger causality and correlation". The wavelet analysis has been frequently used in contemporary economics, finance, and environmental studies (Al-Yahyaee et al., 2019; Fareed et al., 2020; Goodell \& Goutte, 2020). This technique does not have a prerequisite for the data to be stationary (Ng \& Chan, 2012). The other advantages of using it include extraction of associations in the short-run, medium-term, and long run, and at different frequencies and time scales in the same estimation (Iqbal et al., 2020).

\subsection{Continuous wavelet transforms (CWT)}

To decompose the data series into time-frequency space, we employ the continuous wavelet transform. Such a decomposition helps to get the information from the local neighborhood by using the 'Morlet Wavelet' function. The main purpose of using wavelet transformation is to decompose and then rebuild the function $x(t) \in L^{2}(\mathbf{R})$. The CWT can be expressed mathematically as under; 
$W_{n}^{X}(s)=\sqrt{\frac{\delta t}{s}} \sum_{n^{\prime}=1}^{N} x_{n^{\prime}} \psi_{0}\left[\left(n^{\prime}-n\right) \frac{\delta t}{s}\right]$,

Where $\mathrm{n}=1, \ldots . \mathrm{N}$, and $\mathrm{s}$ represents the set of scale and $\delta t$ denotes the time step $(\mathrm{Ng} \&$ Chan, 2012).

\subsection{Wavelet Transform Coherence (WTC)}

The wavelet coherence provides the localized correlation coefficient of two time series $\mathrm{X}=[\mathrm{Xn}]$ and $\mathrm{Y}=[\mathrm{Yn}]$ in the time-frequency domain. The WTC is calculated as the absolute square value of smoothed "cross-wavelet spectra" for both time series (X and $\mathrm{Y}$ ) divided by the product of the smoothed individual "wavelet power spectra" of X and $\mathrm{Y}$.

$R^{2}(r, s)=\frac{\mid S\left(\left.s^{-1} W_{x y}(r, s)\right|^{2}\right.}{S\left(s^{-1}\left|W_{x}(r, s)\right|^{2} S\left(s^{-1}\left|W_{y}(r, s)\right|^{2}\right.\right.}$

Where $S$ indicates the smoothing parameter, and when there is no smoothing, the WTC will be equal to 1 . Moreover, the coefficient of squared wavelet coherence satisfies the inequality i.e. $0 \leq$ $\mathrm{R}^{2}(\mathrm{r}, \mathrm{s}) \leq 1$. A value close to 1 means strong correlation, while a value close to zero shows weak correlation. Wavelet coherence between all possible combinations of our pairs of variables for both developed and emerging markets is given as under;

$$
\begin{aligned}
& R\left(I N S_{-} E M, C O V 19\right)=\frac{S\left[W\left(I N S_{-} E M, C O V 19\right)\right]}{\sqrt{S\left[W\left(I N S_{-} E M\right)\right] S[W(C O V 19)]}} \\
& R^{2}\left(I N S_{-} E M, C O V 19\right)=R\left(I N S_{-} E M, C O V 19\right) \cdot R\left(I N S_{-} E M, C O V 19\right)^{*} ; \\
& R\left(I N S_{-} D M, C O V 19\right)=\frac{S\left[W\left(I N S_{-} D M, C O V 19\right)\right]}{\sqrt{S\left[W\left(I N S_{-} D M\right)\right] S[W(C O V 19)]}} ; \\
& R^{2}\left(I N S_{-} D M, C O V 19\right)=R\left(I N S_{-} D M, C O V 19\right) \cdot R\left(I N S_{-} D M, C O V 19\right)^{*}
\end{aligned}
$$


Where COVI9 is the daily new cases worldwide, INS_EM and INS_DM are the Nasdaq insurance market indices for emerging and developed markets, respectively. $S$ is the smoothing parameter. $R$ means coherence, while $R 2$ specifies the squared coherence. Monte Carlo simulation is used to check the level of significance in WTC (Grinsted et al., 2004).

\section{Results and discussion}

Table 1 presents the summary statistics of our variables. It is clearly evident that INS(EM), INS(DM), and COV19 exhibit skewing and heavy-tailed distributions. The Shapiro-Wilk and Jarque-Bera statistics illustrate that the series have leptokurtic and asymmetric distributions, rejecting the null hypothesis of normality and symmetry. Therefore, the wavelet technique is an appropriate selection that explores the co-movements over time and frequency domains instead of evaluating the average statistical relationship between the series (Grinsted et al., 2004).

\section{$<<$ Insert Table 1 here $>>$}

Figure 4 shows the CWT of all the variables by decomposing the series into time and frequency domains. Red areas inside thick black linings show significant variations during those specific time and frequency ranges. The horizontal $(x)$ and vertical $(y)$ axis display the time component and frequency band, respectively. The frequency ranges from scale 4 (four days cycle) to 32 (more than 32 days a cycle). The darker area separates the lighter area by a solid line, indicating a cone of influence (COI) and significant edge effects.

\section{$<<$ Insert Figure 4 here $>>$}

Figure 5 shows the wavelet coherence results between $\mathrm{COV} 19$ and insurance market returns for emerging and developed markets. Small arrows are lying inside the contours with thick black 
lining show significant areas of co-movements in a specific time and frequency bands. The direction of arrows signifies the phase differences. Arrows pointing towards right $(\mathbb{R}$ show inphase (positive association) coherence while arrows directed left $\urcorner$ demonstrate an out-phase (negative association) coherence. The coherence moves from dark blue (low coherency) to dark red (high coherency) to indicate the strength of the co-movement.

\section{$<<$ Insert Figure 5 here $>>$}

In Figure 5(a) there are three significant and noticeable red contours. The big one contains several arrows [ indicating that COV19 is leading insurance returns in emerging markets with an outphase coherence in the short-run (0-4) and medium-term (4-8) during April and May. This finding is in line with the recent studies concluding a significant negative impact of COVID-19 shock on the insurance industry of China, Turkey, Ethiopia, and Ghana (Babuna et al., 2020; Öztürk et al., 2020; Wang et al., 2020; Worku \& Mersha, 2020). A tiny red contour in the 0-4 frequency band, during mid of April, shows few arrows Z that mean COV19 is leading insurance returns with inphase coherence. This may be due to the dominant and positive effect of Chinese recovery from COVID-19 in April, which is the biggest emerging market. This result supports the literature citing a quick rebound in the market prices after a swift decline due to catastrophic incidents (Brounen \& Derwall, 2010). Finally, a little anomaly can be seen in the third red contour in the short-run during mid-September, where a few arrows ] indicate that COV19 is lagging insurance returns with in-phase coherence. Actually, this is the time when most of the countries ease restrictions on the limited movement of goods and people, which in turn promotes the business and finance activities, including insurance. 
Similarly, in Figure 5(b), there are four noticeable red contours. The one with prominent size contains several arrows [ indicating that COV19 is leading insurance returns with significant out-phase coherence in the short-run (4-8) during mid-April to mid-May for the developed markets. The negative response of insurance returns to COVID-19 shock in developed markets is similar to the findings of other studies reporting a high financial contagion and significant insurance returns decline in response to the crisis events; like the terrorist attacks of $9 / 11$ and the global financial crisis of 2007-08 (Baluch et al., 2011; Cummins \& Weiss, 2009; Marović et al., 2010; Ramiah et al., 2010). However, our results do not support the idea of a low correlation of insurance stock returns with the market portfolio after a financial crisis, as reported by Thomann (2013). Three small red contours exist in the short-run (0-4) during mid-February, and mid-April to mid-May, showing a few arrows ] $\wedge$ indicating a mixed trend.

The swift negative response right after the COVID-19 is also in line with the literature citing high contagion in both emerging and developed markets following a financial crisis event (Aloui et al., 2011). In a nutshell, the impact of COVID-19 on insurance returns is more severe but short-lived for emerging markets. The findings are in line with Marović et al. (2010), suggesting the negative impact of financial disaster on the insurance industry. Moreover, emerging markets have comparatively limited resources to deal with the severe impact of the pandemic and therefore are expected to suffer the worst. Additionally, in developed markets, the low-interest rates throughout the world during the last two decades have been putting a negative strain on the market returns of insurance companies which rely heavily on fixed income markets for investments (Killins \& Chen, 2020). Therefore, the recent decline in insurance returns should be of great concern as the interest rates are still persistently low.

\subsection{Robustness check}


We further apply wavelet-based correlation and Granger causality tests for the robustness check. In this regard, we first decompose all the raw series into different frequencies (D1, D2,..., D6) and a smoothed variable (S6) by employing MODWT based "Least Asymmetric (LA) Wavelet Filter" (Daubechies, 1992). The MODWT follows the Multi-resolution analysis (MRA) of the J=6 pattern for all time series. Figure 6 shows the MODWT decomposition of variables on $\mathrm{J}=6$ wavelet levels.

\section{$<<$ Insert Figure 6 here $>>$}

After decomposing the variables, we employ the wavelet correlation. Figures 7(a) and 7(b) show the wavelet correlations between COV19 and INS for emerging and developed markets, respectively. We observe a negative/positive correlation between COV19 and INS at different timefrequency bands for emerging and developed markets. However, we find a bit stronger wavelet correlation in emerging markets.

\section{$<<$ Insert Figure 7 here $>>$}

Table 2 reports the results of wavelet-based granger causality for emerging and developed markets. COV19 Granger causes insurance returns in the frequency ranges of $\mathrm{d} 2$ (short-run) and $\mathrm{d} 3$ (medium-run) for emerging markets. In contrast, COV19 Granger causes INS(DM) in the shortrun (D1), mid-term (D2), and long-run (D6) for developed markets. These findings are robust to the results of wavelet coherence (WTC). The insignificance of results for other frequency ranges shows the asymmetry in associations between our variables at different scales. 


\section{Concluding remarks}

In the short run and mid-term, COVID-19 caused a decrease in the insurance industry returns of both the emerging and advanced economies. Although both types of economies show some kind of rebound in returns recently, the overall drop in emerging markets is more significant than the developed markets, due to the strong growth prevailing in emerging markets before COVID-19. Further, the impact of COVID-19 is found to be asymmetric on insurance returns in both emerging and advanced economies in varying time-frequency combinations. Immediate policy measures should be taken to support the insurance industry's potential decline, which is already bearing low profitability caused by the persistently low-interest rates in developed markets recently. Our results represent the scenario from COVID-19 until now (September 14, 2020), and the long-term impact will be unraveled in future studies with the passage of time.

\section{Disclosure statement}

No potential conflict of interest was reported by the author(s).

\section{References}

Akhtaruzzaman, M., Boubaker, S., \& Sensoy, A. (2020). Financial contagion during COVID-19 crisis. Finance Research Letters, 101604.

Al-Yahyaee, K. H., Rehman, M. U., Mensi, W., \& Al-Jarrah, I. M. W. (2019). Can uncertainty indices predict Bitcoin prices? A revisited analysis using partial and multivariate wavelet approaches. The North American Journal of Economics and Finance, 49, 47-56.

Aloui, R., Aïssa, M. S. B., \& Nguyen, D. K. (2011). Global financial crisis, extreme interdependences, and contagion effects: The role of economic structure? Journal of Banking \& Finance, 35(1), 130-141.

Azimli, A. (2020). The impact of COVID-19 on the degree of dependence and structure of risk-return relationship: A quantile regression approach. Finance Research Letters, 101648.

Babuna, P., Yang, X., Gyilbag, A., Awudi, D. A., Ngmenbelle, D., \& Bian, D. (2020). The Impact of COVID-19 on the Insurance Industry. International journal of environmental research and public health, 17(16), 5766.

Baek, S., Mohanty, S. K., \& Mina, G. (2020). COVID-19 and Stock Market Volatility: An Industry Level Analysis. Finance Research Letters, 101748.

Baluch, F., Mutenga, S., \& Parsons, C. (2011). Insurance, systemic risk and the financial crisis. The Geneva Papers on Risk and Insurance-Issues and Practice, 36(1), 126-163. 
Brounen, D., \& Derwall, J. (2010). The impact of terrorist attacks on international stock markets. European Financial Management, 16(4), 585-598.

Cepoi, C.-O. (2020). Asymmetric dependence between stock market returns and news during COVID19 financial turmoil. Finance Research Letters.

Chen, S., Yang, Y., \& Lin, J.-H. (2020). Capped borrower credit risk and insurer hedging during the COVID19 outbreak. Finance Research Letters, 101744.

Ciner, C. (2020). Stock Return Predictability in the time of COVID-19. Finance Research Letters, 101705.

Conlon, T., \& McGee, R. (2020). Safe haven or risky hazard? Bitcoin during the COVID-19 bear market. Finance Research Letters, 101607.

Corbet, S., Hou, G., Hu, Y., Larkin, C. J., \& Oxley, L. (2020). Any Port in a Storm: Cryptocurrency Safe-Havens during the COVID-19 Pandemic. Available at SSRN 3610461.

Cummins, J. D., \& Weiss, M. A. (2009). Convergence of insurance and financial markets: Hybrid and securitized risk-transfer solutions. Journal of Risk and Insurance, 76(3), 493-545.

Daubechies, I. (1992). Ten lectures on wavelets: Society for Industrial and Applied Mathematics (SIAM). Philadelphia, $P A$.

Erdem, O. (2020). Freedom and stock market performance during Covid-19 outbreak. Finance Research Letters

Fareed, Z., Iqbal, N., Shahzad, F., Shah, S. G. M., Zulfiqar, B., Shahzad, K., . . Shahzad, U. (2020). Covariance nexus between COVID-19 mortality, humidity, and air quality index in Wuhan, China: New insights from partial and multiple wavelet coherence. Air Quality, Atmosphere, \& Health, 1.

Goodell, J. W. (2020). COVID-19 and finance: Agendas for future research. Finance Research Letters, 101512.

Goodell, J. W., \& Goutte, S. (2020). Co-movement of COVID-19 and Bitcoin: Evidence from wavelet coherence analysis. Finance Research Letters, 101625.

Grinsted, A., Moore, J. C., \& Jevrejeva, S. (2004). Application of the cross wavelet transform and wavelet coherence to geophysical time series.

Iqbal, N., Fareed, Z., Shahzad, F., He, X., Shahzad, U., \& Lina, M. (2020). Nexus between COVID-19, temperature and exchange rate in Wuhan City: New findings from Partial and Multiple Wavelet Coherence. Science of The Total Environment, 138916.

Ji, Q., Zhang, D., \& Zhao, Y. (2020). Searching for safe-haven assets during the COVID-19 pandemic. International Review of Financial Analysis, 101526.

Killins, R. N., \& Chen, H. (2020). The impact of the yield curve on the equity returns of insurance companies. International Journal of Finance \& Economics.

Li, Y., Liang, C., Ma, F., \& Wang, J. (2020). The role of the IDEMV in predicting European stock market volatility during the COVID-19 pandemic. Finance Research Letters, 101749.

Marović, B., Njegomir, V., \& Maksimović, R. (2010). The implications of the financial crisis to the insurance industry-global and regional perspective. Economic research-Ekonomska istraživanja, 23(2), 127141.

Mazur, M., Dang, M., \& Vega, M. (2020). COVID-19 and the march 2020 stock market crash. Evidence from S\&P1500. Finance Research Letters, 101690.

Mensi, W., Sensoy, A., Vo, X. V., \& Kang, S. H. (2020). Impact of COVID-19 outbreak on asymmetric multifractality of gold and oil prices. Resources Policy, 101829.

Michel-Kerjan, E., Raschky, P., \& Kunreuther, H. (2015). Corporate demand for insurance: New evidence from the US terrorism and property markets. Journal of Risk and Insurance, 82(3), 505-530.

Mnif, E., Jarboui, A., \& Mouakhar, K. (2020). How the cryptocurrency market has performed during COVID 19? A multifractal analysis. Finance Research Letters, 101647. 
Ng, E. K., \& Chan, J. C. (2012). Geophysical applications of partial wavelet coherence and multiple wavelet coherence. Journal of Atmospheric and Oceanic Technology, 29(12), 1845-1853.

Okorie, D. I., \& Lin, B. (2020). Stock Markets and the COVID-19 Fractal Contagion Effects. Finance Research Letters, 101640.

Öztürk, Ö., Şişman, M. Y., Uslu, H., \& Çıtak, F. (2020). Effect of COVID-19 outbreak on Turkish stock market: a sectoral-level analysis. Hitit University Journal of Social Sciences Institute, 13(1), 56-68.

Ragin, M. A., \& Halek, M. (2016). Market expectations following catastrophes: An examination of insurance broker returns. Journal of Risk and Insurance, 83(4), 849-876.

Ramiah, V., Cam, M.-A., Calabro, M., Maher, D., \& Ghafouri, S. (2010). Changes in equity returns and volatility across different Australian industries following the recent terrorist attacks. Pacific-Basin Finance Journal, 18(1), 64-76.

Swiss Re (2020). Global insurance industry to recover strongly from COVID-19 induced pull-back, retrieved from:https://www.swissre.com/dam/jcr:4456e0de-f30a-4b2a-943d-336dc8255eb7/nr20200709-sigma-4-2020-en.pdf (Accessed: 18 September 2020).

Thomann, C. (2013). The impact of catastrophes on insurer stock volatility. Journal of Risk and Insurance, 80(1), 65-94.

Topcu, M., \& Gulal, O. S. (2020). The impact of COVID-19 on emerging stock markets. Finance Research Letters, 101691.

Wang, Y., Zhang, D., Wang, X., \& Fu, Q. (2020). How Does COVID-19 Affect China's Insurance Market? Emerging Markets Finance and Trade, 56(10), 2350-2362.

Worku, A., \& Mersha, D. (2020). The Effect of COVID-19 on Insurance Industry in Ethiopia. Journal of Business and economics, 39-44.

World Health Organization (2020). Weekly Operational Update on COVID-19, retrieved from:https://www.who.int/docs/default-source/coronaviruse/situation-reports/wou-18september-2020-cleared.pdf?sfvrsn=be6111c8_2 (Accessed: 18 September 2020).

Zaremba, A., Kizys, R., Aharon, D. Y., \& Demir, E. (2020). Infected Markets: Novel Coronavirus, Government Interventions, and Stock Return Volatility around the Globe. Finance Research Letters, 101597.

Zhang, D., Hu, M., \& Ji, Q. (2020). Financial markets under the global pandemic of COVID-19. Finance Research Letters, 101528. 
Figure 1. Worldwide COVID-19 daily new cases

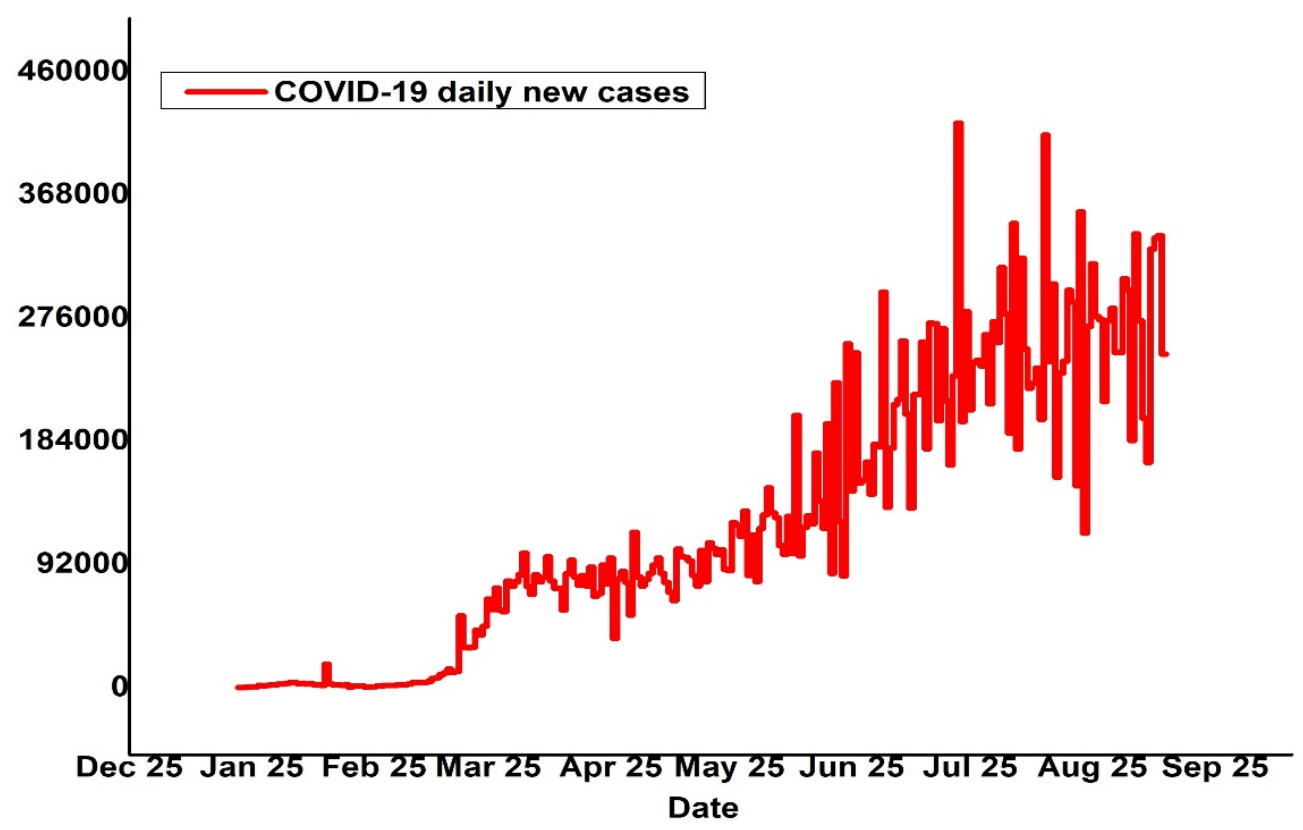

Figure 2. Life and non-life insurance premium growth with respect to GDP growth in emerging and developed markets
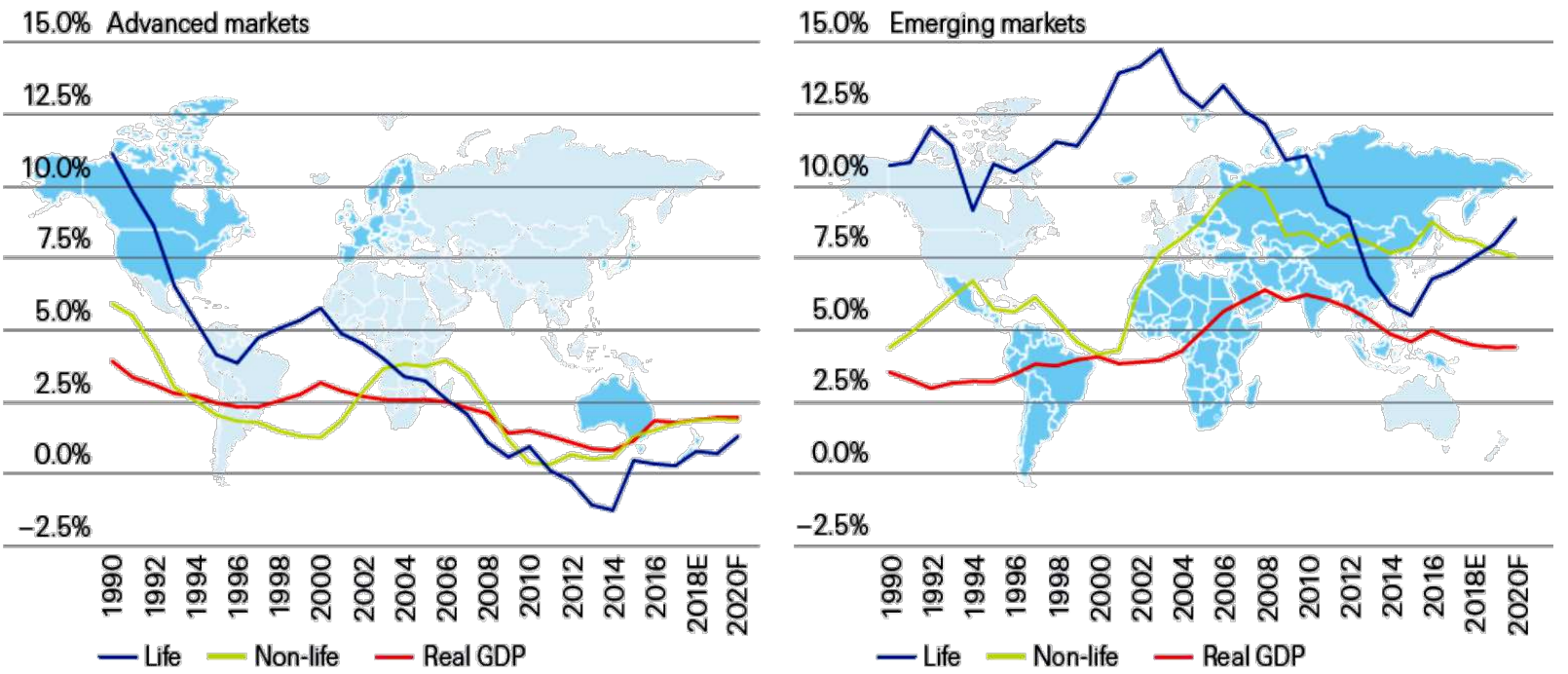

Source: Swiss Re Institute. 2020 
Figure 3. Insurance market returns in emerging and developed markets

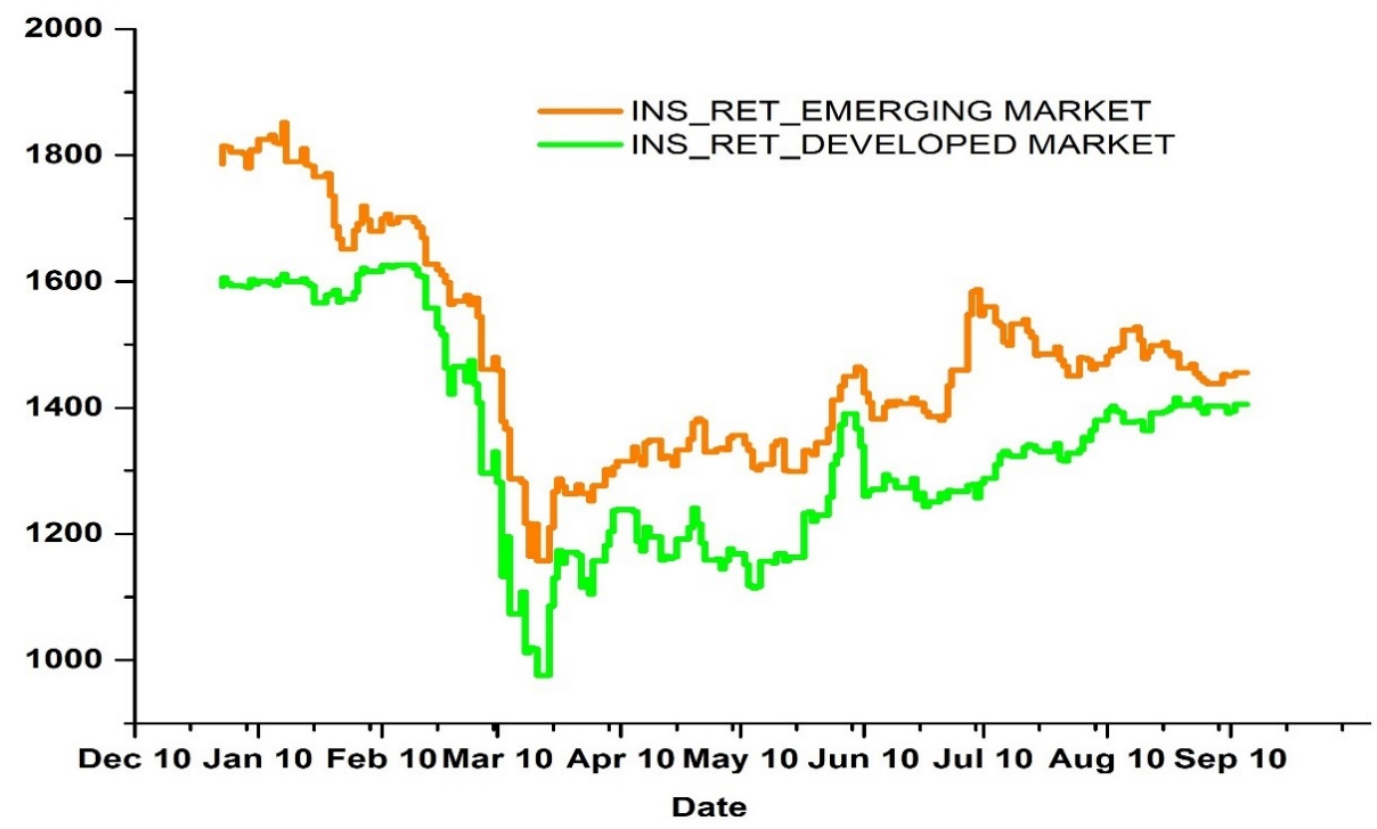


Figure 4. Continuous Wavelet Transform of INS(EM), INS(DM), and COV19

a)

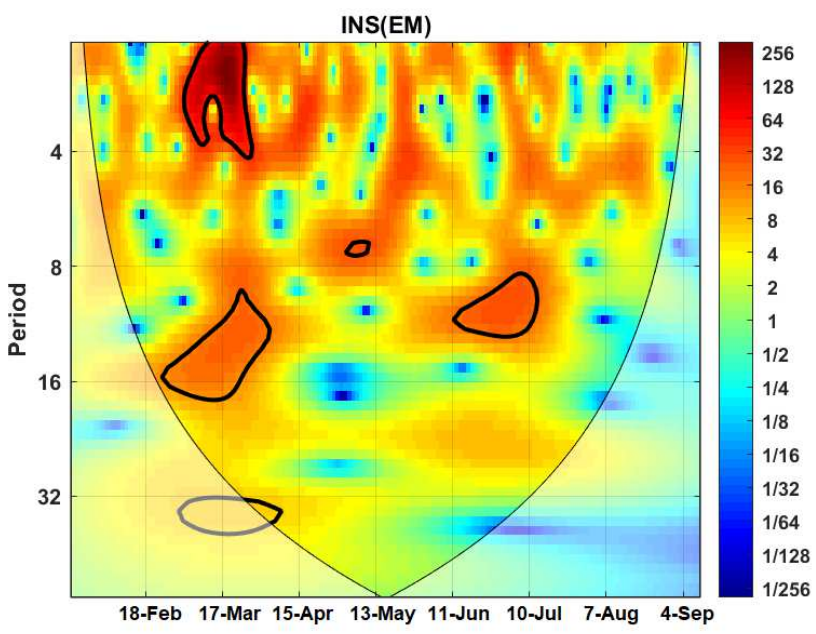

b)

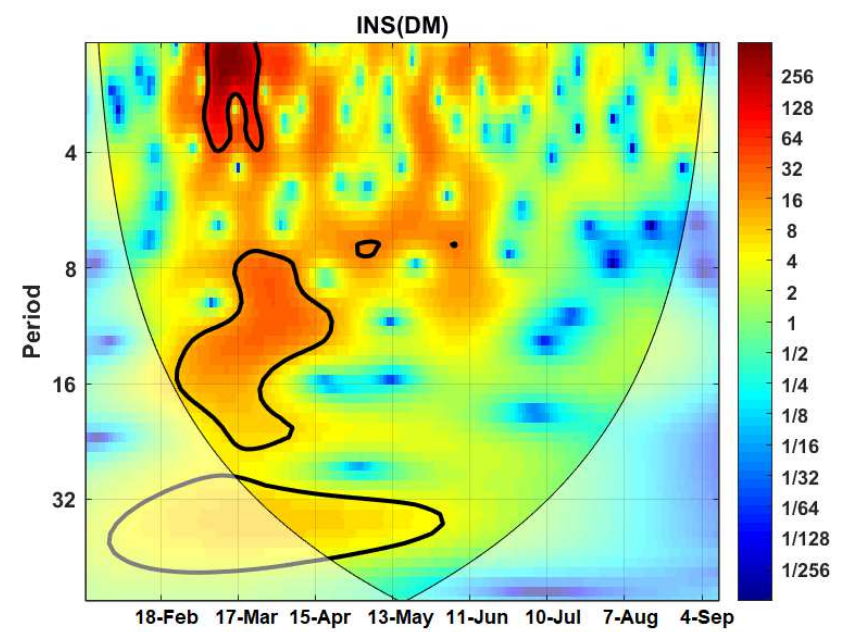

c) 


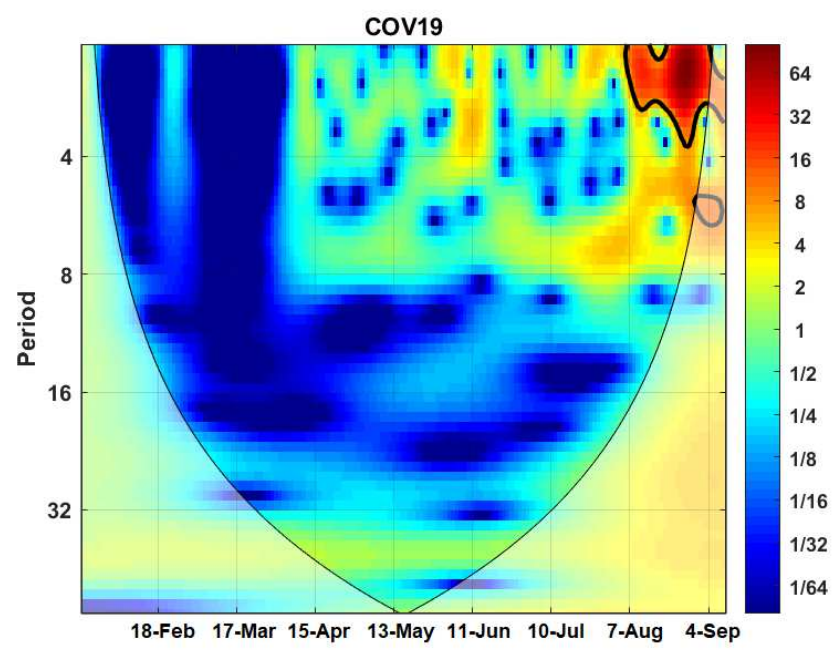

Notes: INS(EM) \& INS(DM) are Nasdaq insurance industry returns for emerging and developed markets, respectively. COV19 is the daily new COVID-19 cases worldwide.

Figure 5. Wavelet Transform Coherence of INS(EM), INS(DM), and COV19

a) Emerging Markets

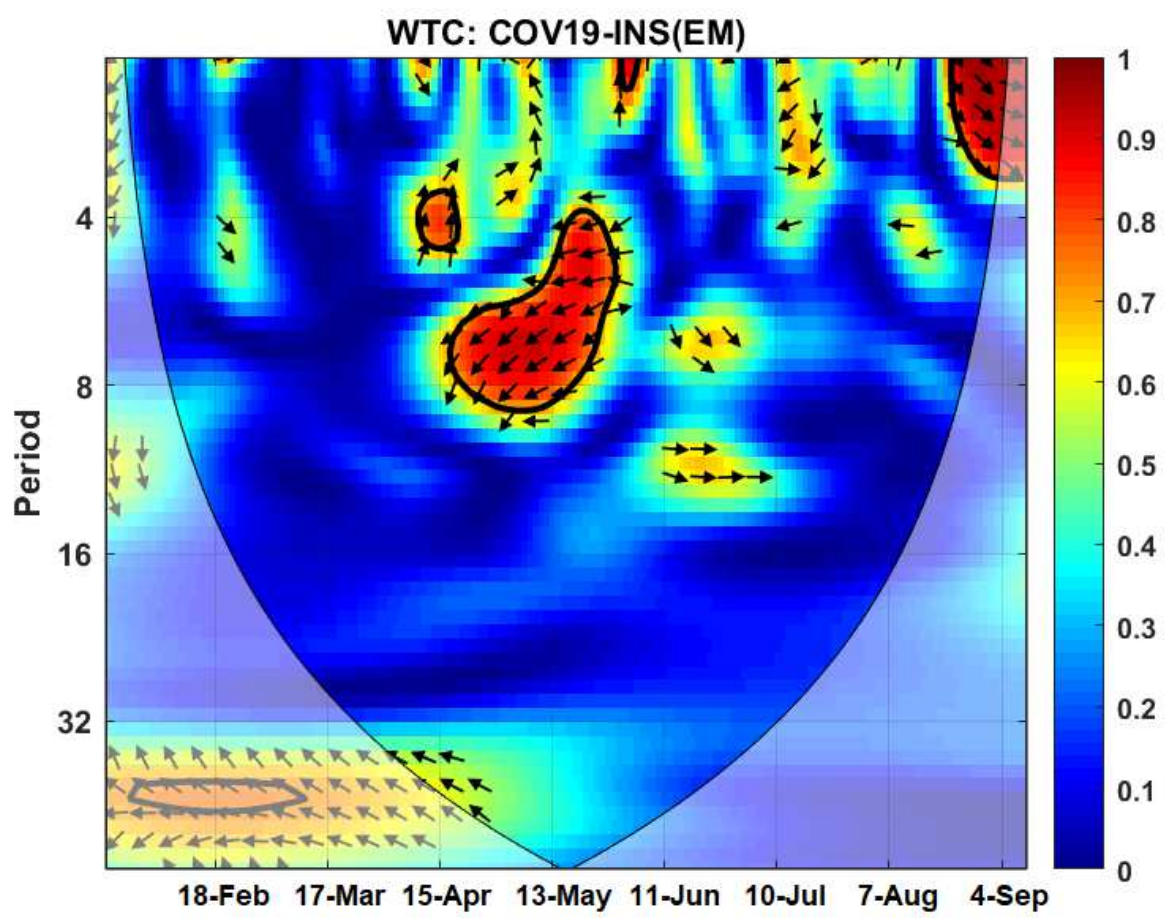

b) Developed Markets 


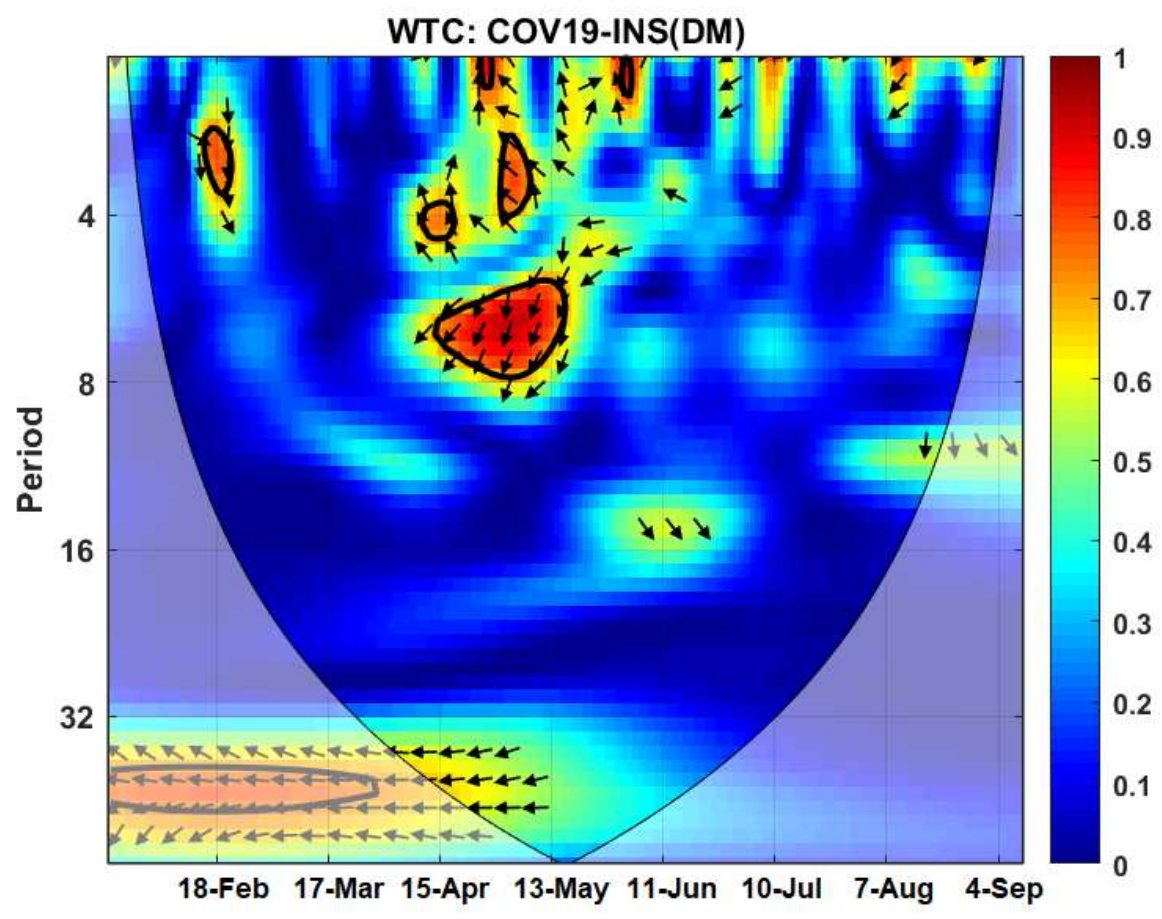

Notes: The $\mathrm{X}$-axis denotes the time, whereas $\mathrm{Y}$-axis shows the frequency period (in days). The thick black contour indicates the $5 \%$ level of significance against the red noise. INS(EM) \& INS(DM) are the Nasdaq insurance industry returns for emerging and developed markets, respectively. COV19 is the daily new COVID-19 cases worldwide. 
Figure 6 MODWT decomposition of variables on $J=6$ wavelet levels

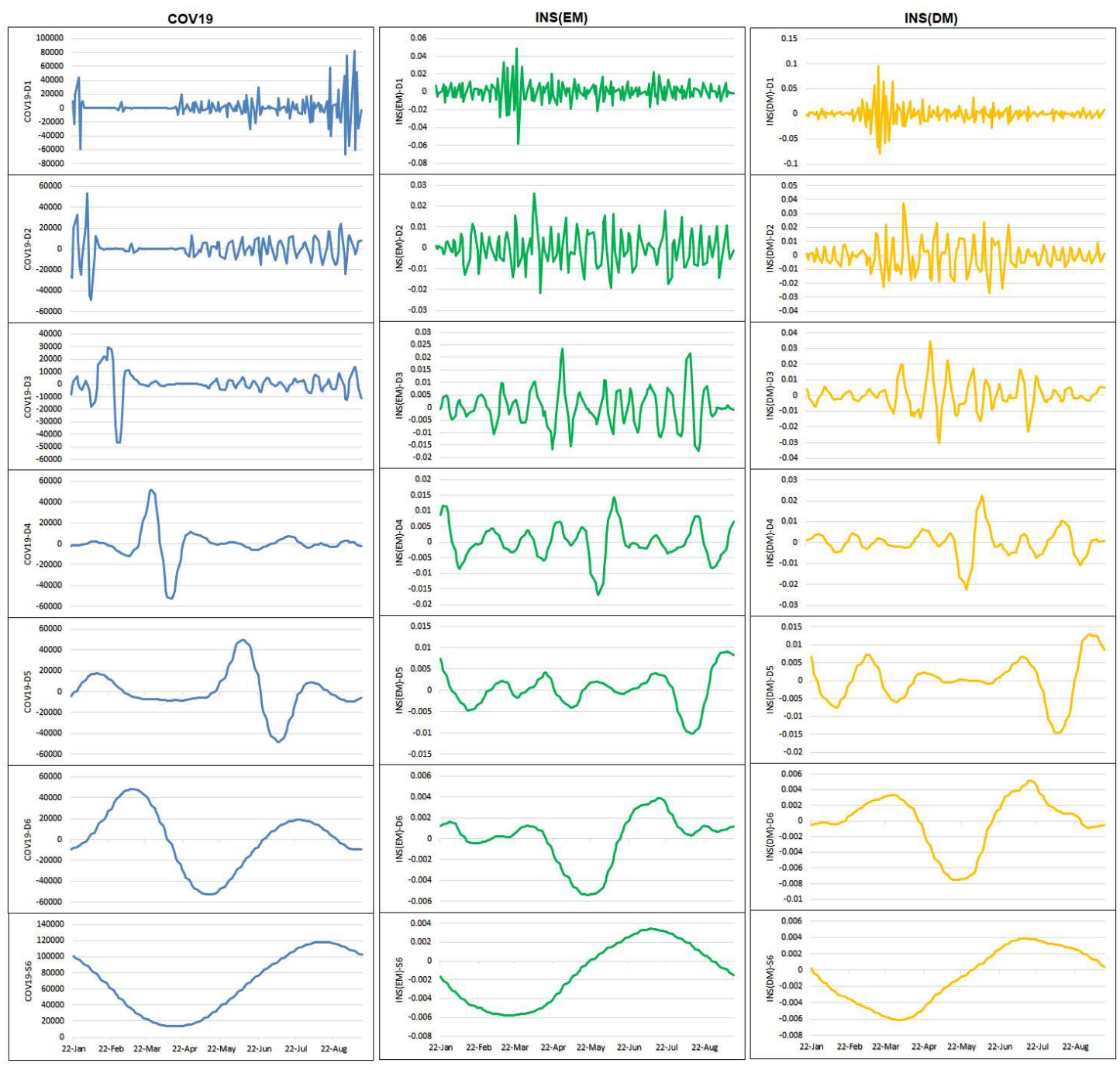


Figure 7. Wavelet correlation analysis between INS(DM), INS(EM), and COV19

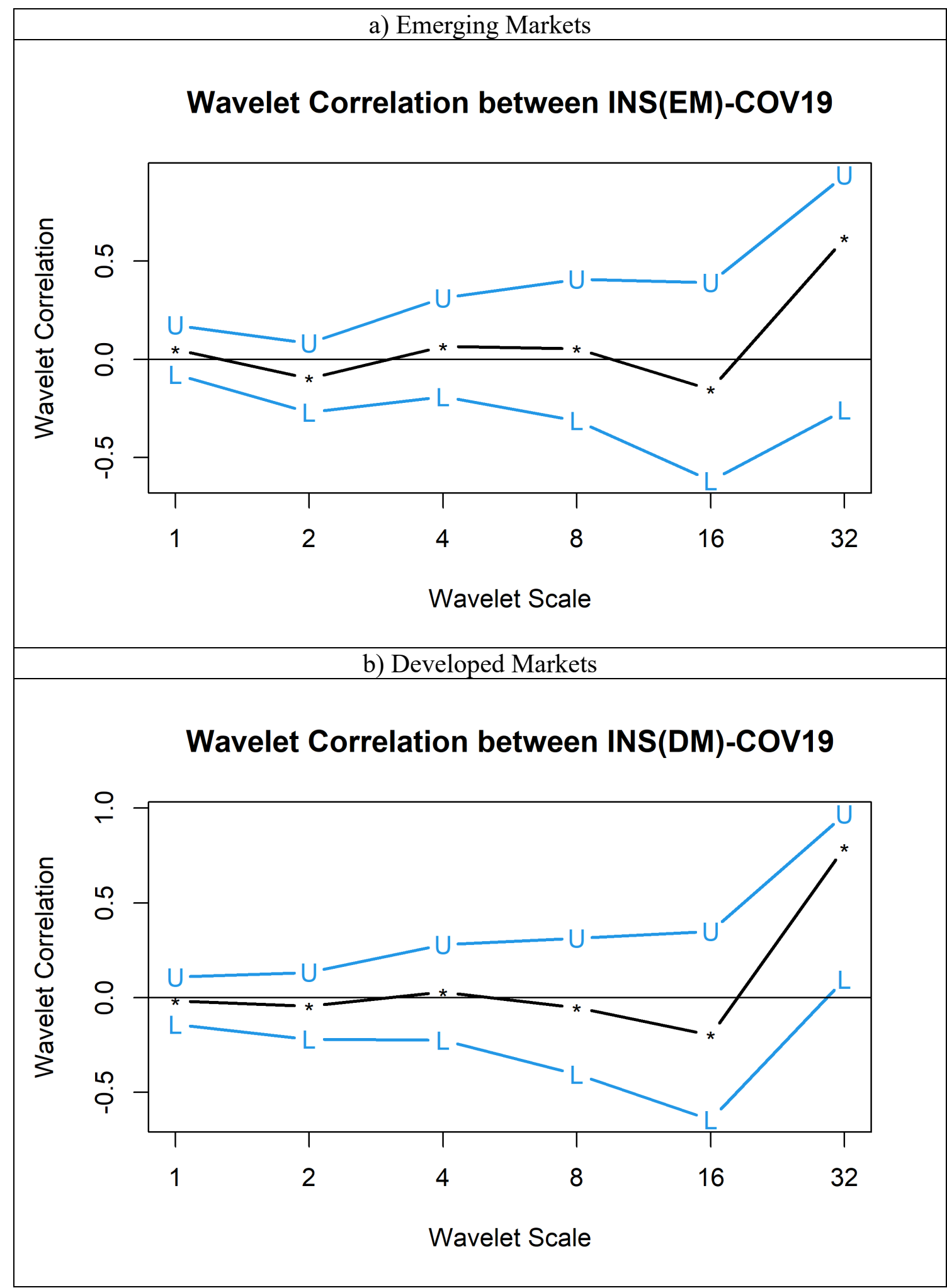

Note: INS(EM) \& INS(DM) are the Nasdaq insurance industry returns for emerging and developed markets, respectively. COV19 is the daily new COVID-19 cases worldwide. 
Table 1. Descriptive Statistics

\begin{tabular}{lccc}
\hline Variable & INS (EM) & INS (DM) & COV19 \\
\hline Obs. & 164 & 164 & 164 \\
Mean & 1453.12 & 1318.279 & 66300 \\
Std. Dev. & 140.0353 & 154.6286 & 57400 \\
Min & 1157.43 & 975.96 & 51 \\
Max & 1810.65 & 1626.24 & 256880 \\
Skew. & 0.4869 & 0.3934 & 0.6568 \\
Kurt. & 2.7114 & 2.5292 & 3.2877 \\
Jarque-Bera & $7.05^{* *}$ & $5.744^{*}$ & $12.36^{* * *}$ \\
Shapiro-Wilk & $0.968^{* * *}$ & $0.957^{* * *}$ & $0.896^{* * *}$ \\
\hline
\end{tabular}

$*, * *, * * *$ show significance at the $1 \%, 5 \%$ and $10 \%$ level. INS(EM) \& INS(DM) are Nasdaq insurance industry returns for emerging and developed markets, respectively. COV19 is the daily new COVID-19 cases worldwide.

Table 2. Wavelet-based Granger causality in emerging and developed markets (Robustness check)

\begin{tabular}{|l|l|l|c|c|c|c|c|}
\hline $\begin{array}{c}\text { Frequency } \\
\text { Domain }\end{array}$ & $\begin{array}{l}\text { Dependent } \\
\text { Variable }\end{array}$ & \multicolumn{2}{|c|}{ Independent Variables } & \multicolumn{2}{c|}{$\begin{array}{l}\text { Dependent } \\
\text { Variable }\end{array}$} & \multicolumn{2}{c|}{ Independent Variables } \\
\hline & & & INS(EM) & COV19 & & INS(DM) & COV19 \\
\hline D1 & INS(EM) & & - & 0.28056 & INS(DM) & - & $26.828^{* * *}$ \\
\hline & COV19 & & 1.8005 & - & COV19 & 2.444 & - \\
\hline D2 & INS(EM) & & - & $51.053^{* * *}$ & INS(DM) & - & $42.459^{* * *}$ \\
\hline & COV19 & & $43.644 * * *$ & - & COV19 & $21.376^{* * *}$ & - \\
\hline D3 & INS(EM) & & - & $9.0392^{* * *}$ & INS(DM) & - & 0.94361 \\
\hline & COV19 & & $5.2298^{* *}$ & - & COV19 & 0.90754 & - \\
\hline D4 & INS(EM) & & - & 2.3542 & INS(DM) & - & 0.62336 \\
\hline & COV19 & & 2.4361 & - & COV19 & 0.48178 & - \\
\hline D5 & INS(EM) & & - & 2.715 & INS(DM) & - & 0.04481 \\
\hline & COV19 & & $8.8432 * * *$ & - & COV19 & 0.04171 & - \\
\hline D6 & INS(EM) & & - & 1.1915 & INS(DM) & - & $12.626^{* * *}$ \\
\hline & COV19 & & 1.0132 & - & COV19 & 5.4515 & - \\
\hline Original & INS(EM) & - & 2.2582 & INS(DM) & - & 3.0501 \\
\hline & COV19 & & 0.35885 & - & COV19 & 0.27157 & - \\
\hline
\end{tabular}

Note: Chi-square values are reported. *,**,*** indicate $10 \%, 5 \%$, and $1 \%$ level of significance, respectively. INS(EM) and INS(DM) are the Nasdaq insurance industry returns for both emerging and developed markets, respectively. COV19 represents the daily new COVID-19 cases worldwide. 
Figures

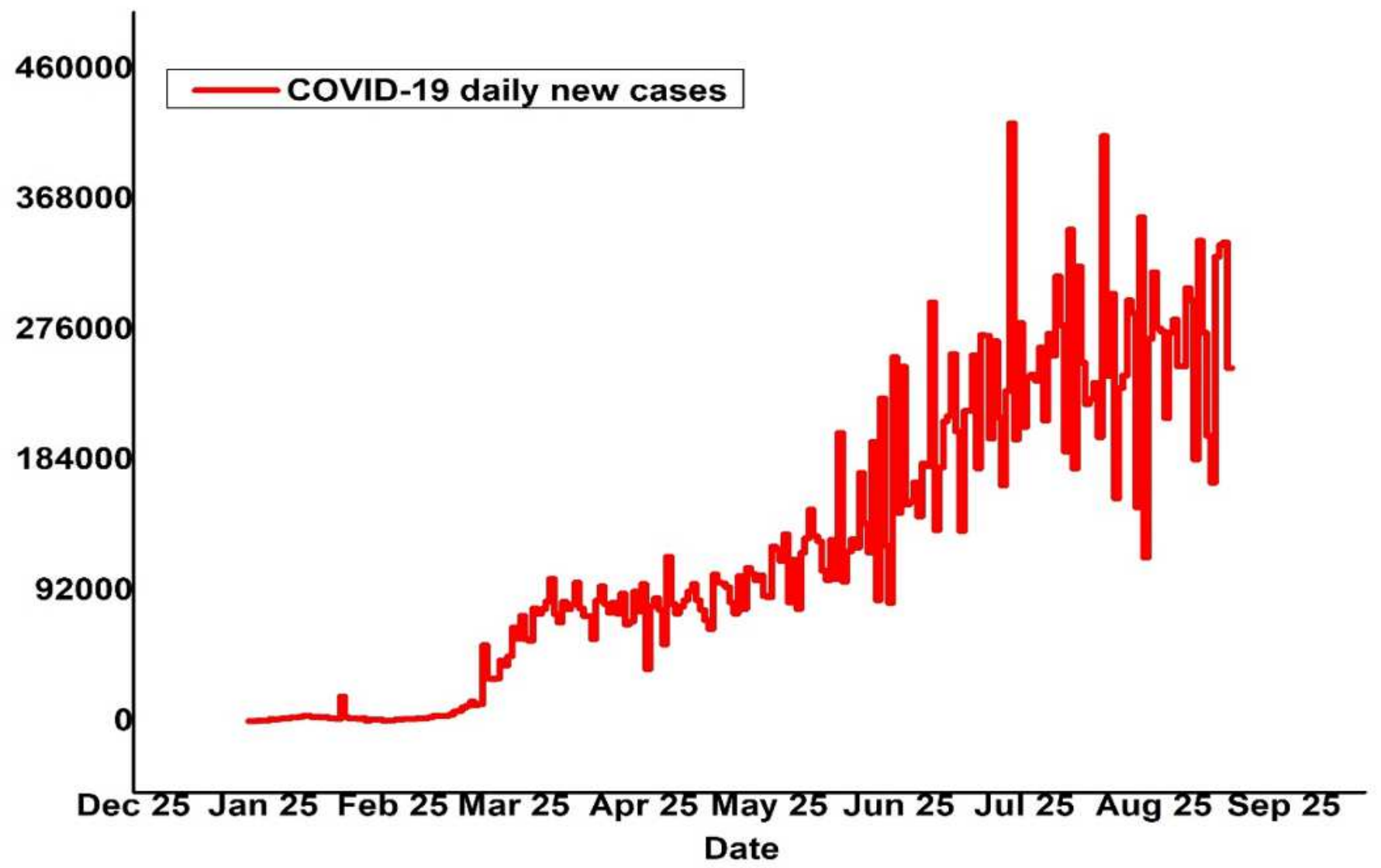

Figure 1

Worldwide COVID-19 daily new cases 

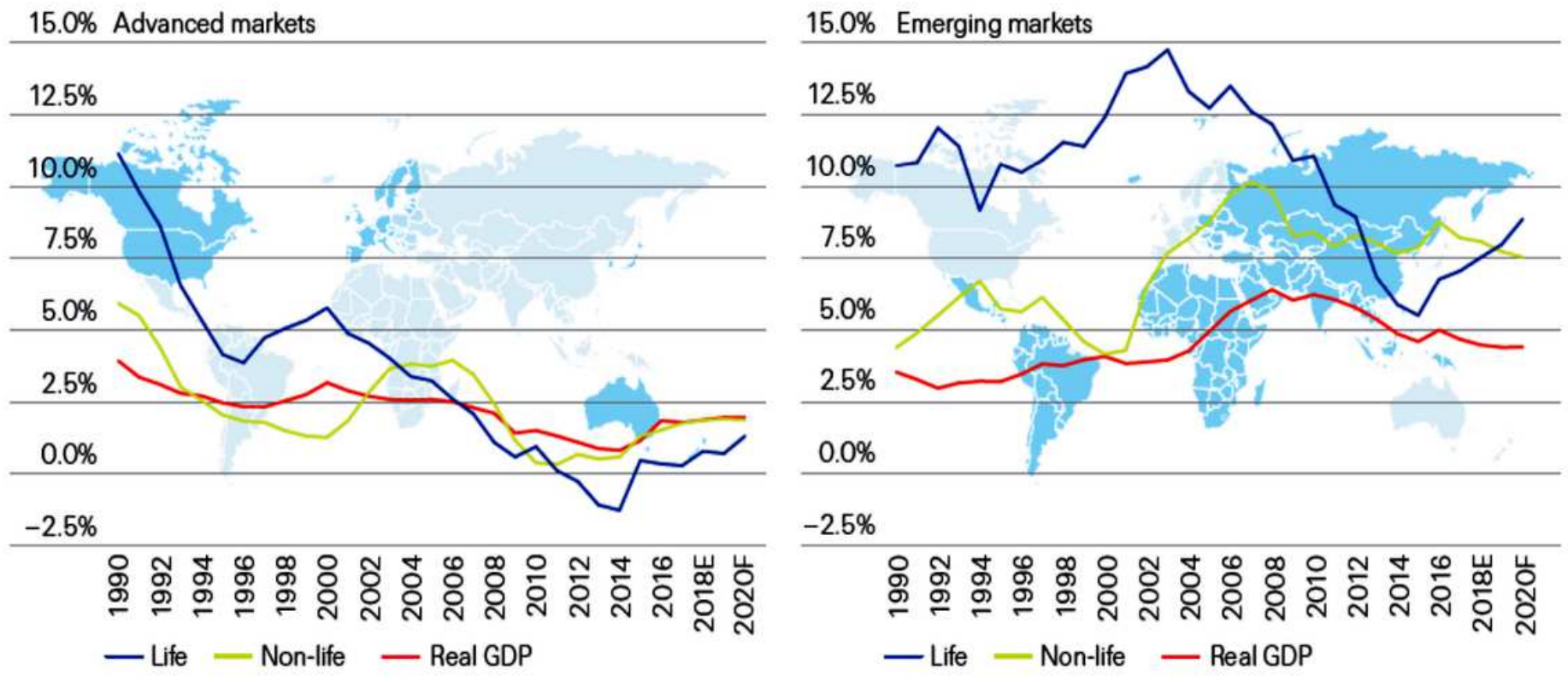

Source: Swiss Re Institute. 2020

\section{Figure 2}

Life and non-life insurance premium growth with respect to GDP growth in emerging and developed markets. Note: The designations employed and the presentation of the material on this map do not imply the expression of any opinion whatsoever on the part of Research Square concerning the legal status of any country, territory, city or area or of its authorities, or concerning the delimitation of its frontiers or boundaries. This map has been provided by the authors. 


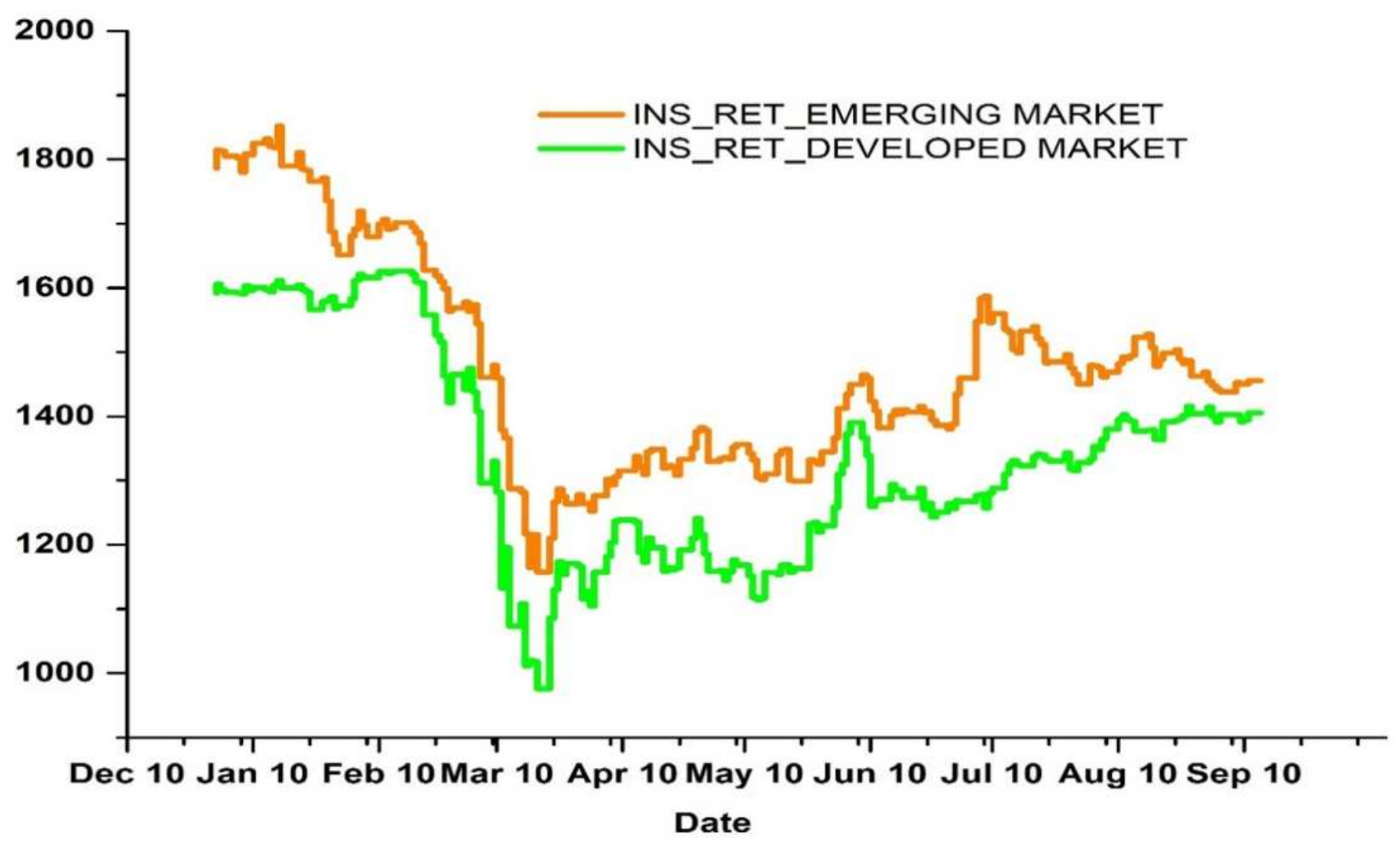

Figure 3

Insurance market returns in emerging and developed markets 
a)

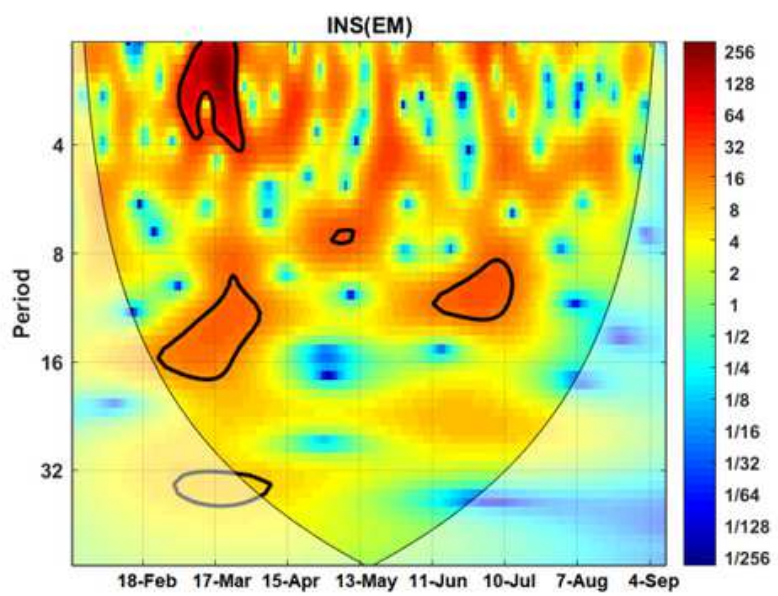

b)
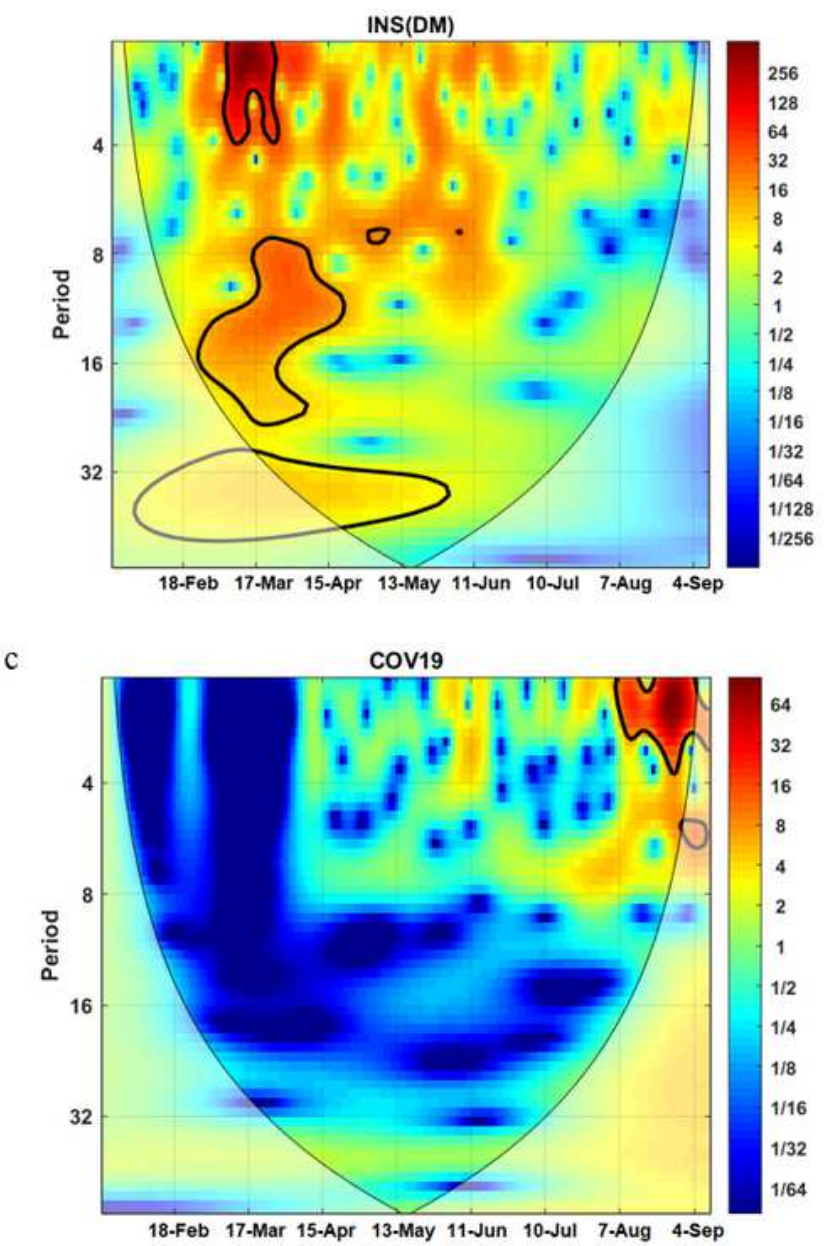

\section{Figure 4}

Continuous Wavelet Transform of INS(EM), INS(DM), and COV19. Notes: INS(EM) \& INS(DM) are Nasdaq insurance industry returns for emerging and developed markets, respectively. COV19 is the daily new COVID-19 cases worldwide. 

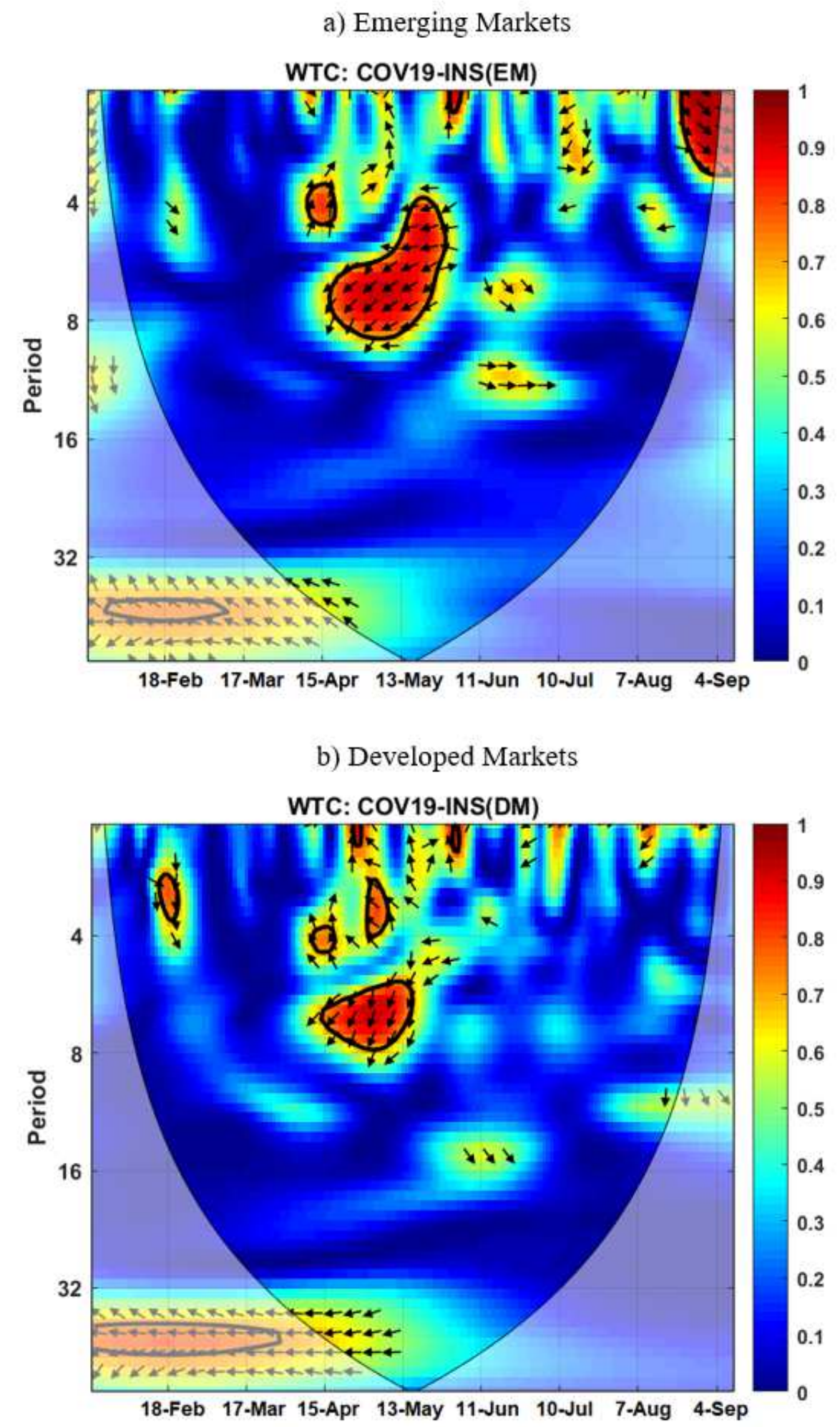

\section{Figure 5}

Wavelet Transform Coherence of INS(EM), INS(DM), and COV19. Notes: The X-axis denotes the time, whereas $\mathrm{Y}$-axis shows the frequency period (in days). The thick black contour indicates the $5 \%$ level of significance against the red noise. INS(EM) \& INS(DM) are the Nasdaq insurance industry returns for emerging and developed markets, respectively. COV19 is the daily new COVID-19 cases worldwide. 


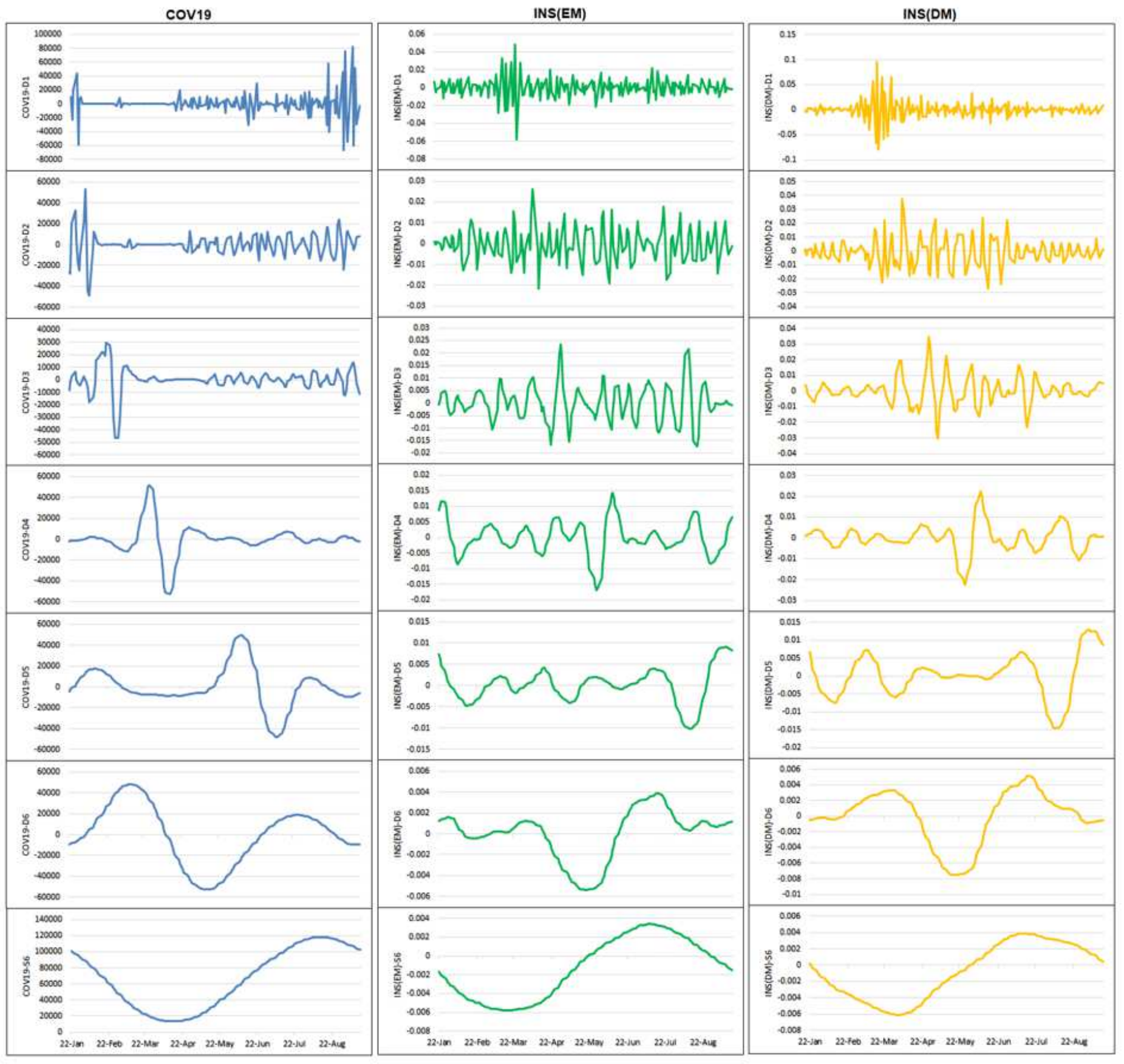

Figure 6

MODWT decomposition of variables on $\mathrm{J}=6$ wavelet levels 


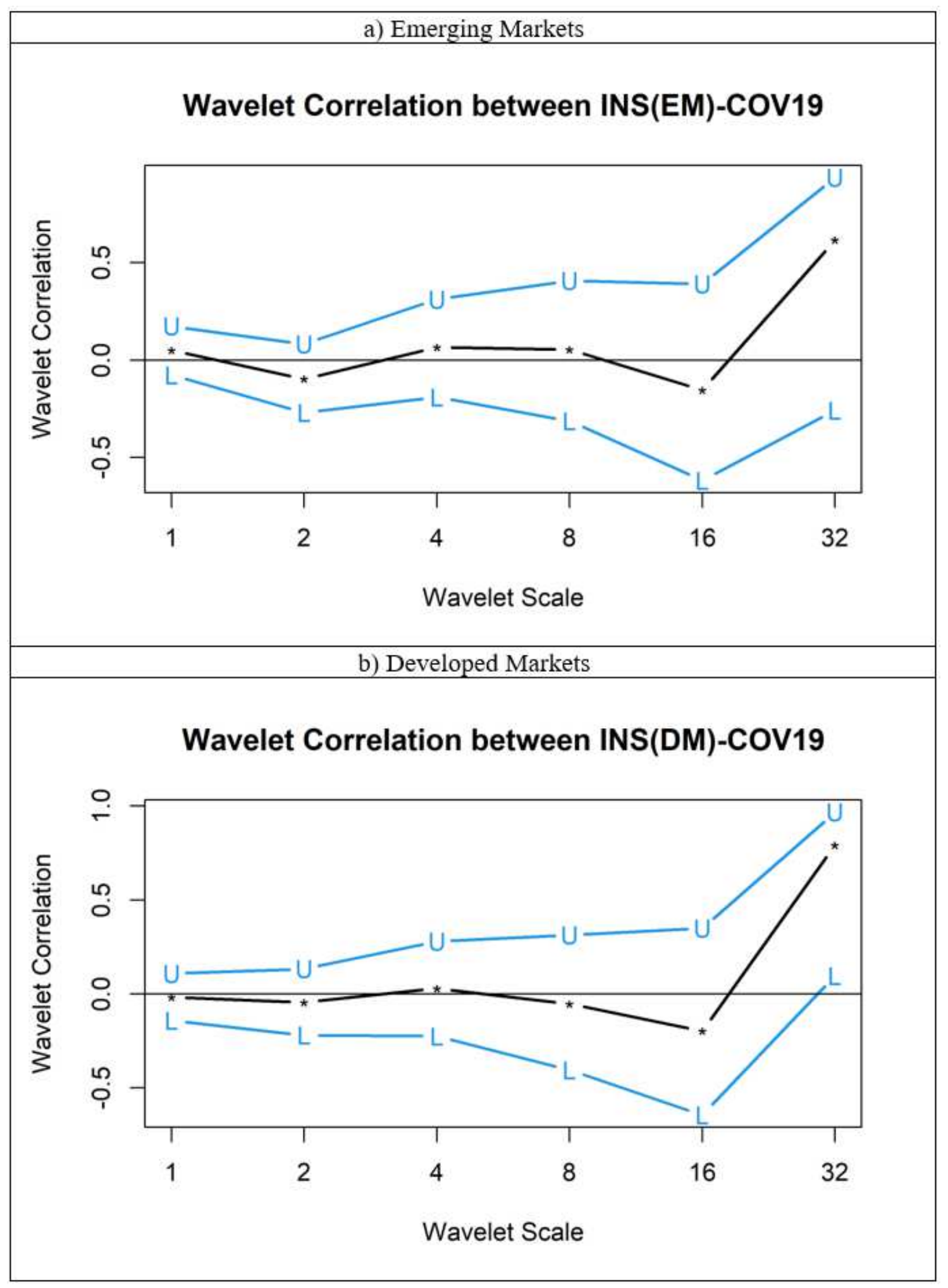

Figure 7

Wavelet correlation analysis between INS(DM), INS(EM), and COV19. Note: INS(EM) \& INS(DM) are the Nasdaq insurance industry returns for emerging and developed markets, respectively. COV19 is the daily new COVID-19 cases worldwide. 